\title{
Volatiles Mediating a Plant-Herbivore-Natural Enemy Interaction in Resistant and Susceptible Soybean Cultivars
}

\author{
Mirian Fernandes Furtado Michereff • Raúl Alberto Laumann • Miguel Borges • \\ Miguel Michereff-Filho • Ivone Rezende Diniz • Austeclínio Lopes Farias Neto • \\ Maria Carolina Blassioli Moraes
}

Received: 11 August 2010 /Revised: 7 December 2010 / Accepted: 31 January 2011 / Published online: 12 February 2011

(C) Springer Science+Business Media, LLC 2011

\begin{abstract}
Several studies have shown that herbivore-induced plant volatiles act directly on herbivores and indirectly on their natural enemies. However, little is known about the effect of herbivore damage on resistant and susceptible plant cultivars and its effect on their natural enemies. Thus, the aim of this study was to evaluate the attraction of the herbivorous pentatomid bug Euschistus heros and its egg parasitoid Telenomus podisi to two resistant and one susceptible soybean cultivars with different types of damage (herbivory, herbivory+oviposition, and oviposition). In a Y-tube olfactometer, the parasitoids were attracted to herbivory and herbivory+oviposition damaged soybean plants when compared to undamaged soybean plants for the resistant cultivars, but did not show preference for the susceptible cultivar Silvânia in any of the damage treatments. The
\end{abstract}

M. F. F. Michereff - R. A. Laumann · M. Borges •

M. C. B. Moraes $(\bowtie)$

Embrapa Recursos Genéticos e Biotecnologia,

Brasília, Brazil

e-mail: mcbmorae@cenargen.embrapa.br

M. F. F. Michereff $\cdot$ I. R. Diniz

Departamento de Zoologia, Universidade de Brasília, Brasília, Brazil

M. Michereff-Filho

Embrapa Hortaliças,

Brasília, Brazil

A. L. Farias Neto

Embrapa Cerrados,

Brasília, Brazil

M. C. B. Moraes

Embrapa Recursos Genéticos e Biotecnologia-Parque Estação

Biológica-W5 Norte,

CEP 70770-900 Brasília, DF, Brazil plant volatiles emitted by oviposition-damaged plants in the three cultivars did not attract the egg parasitoid. In four-arm-olfactometer bioassays, E. heros females did not show preference for odors of damaged or undamaged soybean plants of the three cultivars studied. The Principal Response Curves (PRC) analysis showed consistent variability over time in the chemical profile of volatiles between treatments for the resistant cultivar Dowling. The compounds that most contributed to the divergence between damaged soybean plants compared to undamaged plants were $(E, E)$ - $\alpha$-farnesene, methyl salicylate, $(Z)$-3hexenyl acetate, and (E)-2-octen-1-ol.

Key Words Euschistus heros . Telenomus podisi - Stink bug · Tritrophic interactions · Indirect defense

\section{Introduction}

Plants are equipped with several mechanisms to defend themselves against herbivores, microbial pathogens, or abiotic stress. One of the mechanisms of damage-induced plant defense is the production of plant volatile organic compounds (VOCs) that serve as repellents to herbivores or as attractants to parasitoids and predators (Price, 1997; De Moraes et al., 2001; Hilker and Meiners, 2006; Chen, 2008; Heil, 2008).

Plants change the blend of VOCs in response to damage either qualitatively or quantitatively (Dicke, 1999), depending mainly on plant traits that vary among species or genotypes and on the different herbivore species causing the damage (Lin et al., 2008; Rasmann and Turlings, 2008). This change can be responsible for differential attraction of parasitoids and predators (Fritzsche Hoballah and Turlings, 2001). Soybean plants, Glycine max L. (Fabales: Fabaceae) 
and pigeon pea, Cajanus cajan (Valder) (Fabales: Fabaceae) damaged by Euschistus heros (Fabricius) (Hemiptera: Pentatomidae) released similar chemical profiles of volatiles that attracted the egg parasitoid Telenomus podisi (Ashmead) (Hymenoptera: Scelionidae). However, when soybean was damaged by feeding Anticarsia gemmatalis Hübner (Lepidoptera: Noctuidae) larvae, the chemical profile was different and did not attract T. podisi (Moraes et al., 2005).

The identification of chemicals responsible for plant defense and their role in the interactions with natural enemies could be used to attract and retain parasitoids in crops (Gatehouse, 2002) and help breeders in the development of cultivars resistant to pests (Piubelli et al., 2005). Therefore, it is important that hostplant resistance interacts positively with the action of natural enemies. However, this association does not always result in positive interactions. Chemical and morphological plant traits can directly influence survival, fecundity, and foraging success of natural enemies on hosts or prey. These traits also can have indirect effects on the quality of herbivores that in turn affects the physiology, behavior, or development of their natural enemies (Cortesero et al., 2000). In a study investigating the effects of chemical plant resistance against herbivores and of predators on plant fitness, Bartlett (2008) observed a negative interaction between the predator Podisus maculiventris (Say) (Hemiptera: Pentatomidae) and soybean resistance against Epilachna varivestis Mulsant (Coleoptera: Coccinellidae).

Studies on resistance of soybean cultivars primarily involve direct defense against herbivory during the reproductive stage of soybean (Piubelli et al., 2005; Li et al., 2004, 2008). Carrão-Panizzi and Kitamura (1995) reported that the cultivar IAC100 contains high quantities of isoflavones compared to other soybean cultivars studied and showed high resistance to herbivorous stink bugs. The resistance of IAC100 to stink bugs and lepidopteran larvae was confirmed by McPherson and Buss (2007) and Piubelli et al. (2005) who proposed an antibiotic effect of this cultivar on velvetbean caterpillars, A. gemmatalis. The soybean cultivar Dowling shows antixenotic and antibiotic effects against aphids, which stop feeding and cause death after $48 \mathrm{hr}$ (Li et al., 2004, 2008).

However, except for these studies of direct effects of soybean cultivar resistance on herbivores, no study has yet addressed the question how resistant traits of the vegetative stages of soybean cultivars affect the plant's indirect defense against herbivores. For Integrated Pest Management in soybean crops, it has been proposed that natural enemies could be released or attracted to the field before herbivorous stink bugs arrive (Borges et al., 1998). Therefore, it is important that the development of resistant cultivars does not alter plant responses to herbivore damage and the release of herbivory-induced volatiles that attract natural enemies.

In this study, we tested the hypothesis that the level of indirect defense in response to damage by herbivores in resistant soybean cultivars is different from that of susceptible cultivars. Hence, we compared chemically the blend of herbivore-induced volatiles in resistant and susceptible cultivars during the vegetative stages. In addition, we compared the behavioral response of both herbivores and their parasitoids to induced volatiles released by the different cultivars. We chose two different cultivars that are known to display resistance against herbivores (IAC100 and Dowling) and one cultivar that shows high susceptibility to stink bugs (Silvânia) (Laumann et al., 2008). The studied herbivorous insect was the stinkbug E. heros and its egg parasitoid T. podisi.

Specifically, we studied the following questions: (a) Does $T$. podisi respond differently to resistant and susceptible cultivars when exposed to undamaged plants or plants damaged by herbivory and oviposition by $E$. heros? (b) Are E. heros females attracted to the volatiles of undamaged or damaged soybean cultivars? (c) Do resistant and susceptible soybean cultivars release a different chemical profile of volatiles when submitted to herbivory, herbivory+oviposition, or oviposition damage by $E$. heros? (d) Does attraction of T. podisi depend on the extent of herbivore damage?

\section{Methods and Materials}

Plant and Insect Rearing Soybean (cultivars Dowling, IAC100 and Silvânia) seeds were obtained from the Embrapa Cerrados Research Center (Brasília, DF, Brazil). Seeds were germinated on damp paper, and after 3 day they were transplanted to pots with a mixture of soil and organic substrate (in a proportion of 1:1 w/w). Plants were kept in a controlled environment room at L14:D10 photoperiod, 27 \pm $1{ }^{\circ} \mathrm{C}$ and $65 \pm 10 \%$ r.h. All plants used were in the V3 physiological stage (Fehr et al., 1971).

Euschistus heros individuals were obtained from a laboratory colony started from adults collected in soybean fields near Embrapa Genetic Resources and Biotechnology, Brasília, Brazil $\left(15^{\circ} 47^{\prime} \mathrm{S}, 47^{\circ} 55^{\prime} \mathrm{W}\right)$. Bugs were reared in 81 plastic containers, on a diet of soybeans, sunflower seeds (Helianthus annus), raw peanuts (Arachis hypogaea), fresh green beans (Phaseolus vulgaris), and water. The food supply was renewed twice a week. To provide oviposition substrate and shelter for the bugs, a piece of a nylon mesh screen $\left(15 \mathrm{~cm}^{2}\right)$ was placed inside the cages. To obtain virgin females, insects were sexed after their imaginal molt and cuticular hardening, and maintained isolated from males until their use in experiments. 
The egg parasitoid T. podisi was obtained from a laboratory colony raised on eggs of $E$. heros. The wasps were maintained in acrylic cages $\left(25 \mathrm{~cm}^{2}\right.$ tissue culture flask, angled neck; ICN Biomedicals, Irvine, CA, USA), and fed with a drop of honey, supplied twice a week. Once parasitoids hatched from eggs, they were transferred to an egg-free acrylic cage where they could mate for a period of $24 \mathrm{hr}$. Euschistus heros and T. podisi were maintained in separate environmental rooms at $27 \pm 1^{\circ} \mathrm{C}, 65 \pm 10 \%$ r.h., and a $14 \mathrm{hr}$ photoperiod.

Preparation of Plants for Bioassays We studied the attraction of $T$. podisi to the three soybean cultivars (cv) that had been subjected to following treatments: (1) herbivory damaged soybean (Herb): five virgin, sexually immature E. heros females (2-4 day-old) were placed on the plant; (2) herbivory+oviposition damaged soybean (HerbOvi): five mated E. heros females (12-15 day-old) were placed on the plant; (3) oviposition damaged soybean (Ovi): five mated $E$. heros females, with their stylet removed using dissection scissors, were placed on the plant; (4) control: undamaged soybean (UD). For treatments, each plant was kept in a micropore plastic bag (bread bag) where the insects were introduced. Plants were used 24, 48, 72, 96, and $120 \mathrm{hr}$ after damage, with 60 replicates for each time/treatment combination. All insects were removed from the plants a few minutes before the bioassays.

We studied the preference behavior of $E$. heros females by using soybean plants that had been submitted to the same treatments as described above. All bioassays were carried out using plants on the 4th $\mathrm{d}$ of damage, because preliminary results showed that natural enemies respond to damaged plants only on the 4th $\mathrm{d}$, and the chemical analysis of the extracts collected from the air-entrainment also showed higher levels of volatiles released on the 4 th $d$

Olfactometer Bioassays with Egg Parasitoids To determine if herbivory- or oviposition-induced volatiles have an effect on the foraging behavior of parasitoids, individual naïve female parasitoids were offered a choice between odors in a Y-shaped olfactometer. A square acrylic block $(19 \times 19 \mathrm{~cm})$ with a Y-shaped cavity (1 cm thickness) sandwiched between two glass plates was used as the bioassay arena (Moraes et al., 2005). The trunk of the apparatus measured $8 \mathrm{~cm}$, and each arm $7 \mathrm{~cm}$. Damaged or undamaged plants were placed in glass chambers that were connected to the olfactometer via silicon tubing. Filtered (activated charcoal) and humidified air was pushed through the system at $0.6 \mathrm{l} /$ min, and pulled through at $0.2 \mathrm{l} / \mathrm{min}$, in a push-pull system. The behavior of the insect was monitored by a camera (CCD camera Sony SPT M324CE; Sony, Minato-Ku, Tokyo, Japan fitted with a $12.5-75.0 \mathrm{~mm} / \mathrm{F} 1.8$ zoom lens) coupled to SACAM software (Jorge et al., 2005) to register behavioral parameters. A single T. podisi female was introduced at the base of the Y-tube and observed for $600 \mathrm{sec}$, and the first choice in each arm was recorded by the software. The first choice was considered to have been made when the insect entered an arm and remained there for at least $20 \mathrm{sec}$. Each individual was used only once, and the plants were replaced after every five repetitions. The position of the arms of the olfactometer was changed after every five bioassays in order to avoid any bias in the parasitoid response. The response of the parasitoid females was tested for each combination as follows: (1) Herb vs. UD $(N=60)$; (2) HerbOvi vs. UD $(N=60)$, and (3) Ovi vs. UD $(N=60)$. The bioassays were carried out for each soybean cultivar $24,48,72,96$, and $120 \mathrm{hr}$ after the start of damage. The damaged and undamaged plants were kept under the same conditions, but in different rooms to avoid plant-plant signalling, until used in the bioassays.

Olfactometer Bioassays with Herbivore Females A fourarm-olfactometer modified from Vet et al. (1983) was used with $E$. heros females. The olfactometer consisted of a square acrylic block $(44 \times 44 \mathrm{~cm})$ with an $\mathrm{X}$-shaped cavity $(1.5 \mathrm{~cm})$ sandwiched between two glass plates, and it was used as the bioassay arena. The " $\mathrm{X}$ " of the apparatus measured $37 \mathrm{~cm}$, and length of the active area for each arm was $25 \mathrm{~cm}$. The length of each arm considered for a positive response of the insects was $15 \mathrm{~cm}$, measured from the upwind end towards the center of the olfactometer. The bioassay procedure was the same as described for the Yolfactometer above. The first choice was considered to have been made when the insect entered an arm and remained there for at least $60 \mathrm{sec}$. The responses of 70 stink bug females were tested for each combination: (1) Herb vs. HerbOvi vs. Ovi vs. UD for each soybean cultivar (cv) with $96 \mathrm{hr}$ of damage and (2) UD of cv Dowling vs. UD cv IAC100 vs. UD cv Silvânia vs. air. For each combination, we tested females in different physiological conditions: (a) starved virgin females (the diet was removed $24 \mathrm{hr}$ before the bioassay); (b) fed virgin females; and (c) fed mated females.

Volatile Analysis Herb-, HerbOvi-, Ovi-, and UD-plants were placed individually in cylindrical glass chambers (internal volume $10 \mathrm{l}$ ). Volatiles were collected for $24 \mathrm{hr}$, during seven consecutive days $(N=11$ replicates for each treatment). In an attempt to minimize contamination by volatiles from the soil, pots were wrapped in aluminium foil. A glass tube containing the adsorbent Super Q (100 mg, 80-100mesh, Alltech PA, USA) was connected via a PTFE tube to a vacuum pump at a flow of $0.6 \mathrm{l} / \mathrm{min}$, and the air entrance was connected to a flow of air filtered with activated charcoal $(1.0 \mathrm{l} / \mathrm{min})$ creating a positive push- 
pull system (Moraes et al., 2008). The trapped volatiles were eluted from the adsorbent using $500 \mu \mathrm{l} n$-hexane and pre-concentrated to $200 \mu \mathrm{l}$ under a $\mathrm{N}_{2}$ flow. Extracts were stored at $-20^{\circ} \mathrm{C}$ until analysis by gas chromatography (GC) and GC coupled to mass-spectrometry (GC-MS).

The extracts obtained by air entrainment were analyzed by GC (Shimadzu 17A, DB-5 column, $30 \mathrm{~m} \times 0.25 \mathrm{~mm}$ ID, $0.25 \mu \mathrm{m}$ film, J\&W Scientific, Folsom, CA, USA), using a temperature program of $50^{\circ} \mathrm{C} / 1 \mathrm{~min}, 15^{\circ} \mathrm{C} / \mathrm{min}$ to $250^{\circ} \mathrm{C} /$ $20 \mathrm{~min}$. The column effluent was analyzed with a flame ionization detector (FID) at $270^{\circ} \mathrm{C}$. For the GC analyses, $50 \mu \mathrm{l}$ of each extract were separated, and $1 \mu \mathrm{l}$ of 1-octen-3-ol was added as internal standard (IS), for a final concentration of $9.8 \mu \mathrm{g} / \mathrm{ml}$ of the IS. One microliter of each sample was injected in splitless mode with helium as carrier gas. Amounts released by the plant in each $24 \mathrm{hr}$ period were calculated in relation to the area of the internal standard. Data were collected with ClassGC software and were handled using Excel Software (Microsoft Corporation 2003).

For qualitative analysis, selected extracts were analyzed using a Shimadzu QP2010 instrument equipped with a quadrupole analyzer, a non-polar DB-5 column (30 $\mathrm{m} \times$ $0.25 \mathrm{~mm}$ ID, $0.25 \mu \mathrm{m}$ film, J\&W Scientific, Folsom, CA, USA) and a splitless injector, with helium as the carrier gas. Ionization was by electron impact (70-eV, source temperature $200^{\circ} \mathrm{C}$ ). Data were collected and analyzed with GCMS Solutions 2.4 Software (Shimadzu Corporation, Japan). Identifications were made by comparison of spectra with library databases (NIST 2005) or with published spectra and confirmed by using authentic standards when available.

Chemicals Super Q (80/100 mesh) was purchased from Alltech (PA, USA). n-Hexane (95\% pesticide residue) was purchased from Fisher Scientific (Loughborough, Leicestershire, UK). (E)-2-Hexenal and (Z)-3-hexen-1-ol were purchased from Sigma Aldrich (Gillinghan, Dorset, UK). (Z)-3-Hexenyl acetate was purchased from Alfa Aesar (Heysham, UK) and $(E)$-ocimene from Botanix (Paddock Wood, Kent, UK). Limonene and linalool were purchased from TCI America (Portland, OR, USA). Methyl salicylate, $\beta$-caryophyllene, benzothiazole, $\beta$-myrcene, geranyl acetone, and $(E)$-2-hexenyl acetate were purchased from Sigma Aldrich (Steinheim, Germany). (E,E)- $\alpha$-Farnesene was provided by Jeffrey Aldrich (USDA-ARS, USA) and $(E)$ 4,8-dimethylnona-1,3,7-triene (DMNT) and (E,E)-4,8,12trimethyltrideca-1,3,7,11-tetraene (TMTT) were provided by Michael Birkett (Rothamsted Research, UK).

Statistical Analysis The null hypothesis of equal preference $(P=0.05)$ of parasitoids for the volatiles from damaged plants vs. undamaged plants was tested at each sampling time (24, 48, 72, 96, and $120 \mathrm{hr}$ ), using chi-square tests with the Yates correction for continuity (Zar, 1998).
Since the volatile sampling was carried out on the same plant at several time points, repeated measures analysis of variance was used to avoid the problem of pseudoreplication during the times analyzed (Hurlbert, 1984; Green, 1993). Therefore, the total amounts of volatiles released in each treatment over time were compared by MANOVA (PROC ANOVA with the PROFILE statement; SAS Institute, 2001), using the subsequent sampling times as repeated measures of the same experimental unit, as suggested by von Ende (1993). Significant data by MANOVA were subjected to post-hoc mean comparisons in individual sampling time using the Tukey's test (significance level 5\%).

The change in the chemical profile of damaged and undamaged soybean plants over time was assessed using Principal Response Curves (PRC) analysis. PRC models the effect of the treatment $d$ at a determined time $t$ in a species $k$. The statistical model for compound concentration is: $\left(y_{d(j) t k}=\mathrm{y}_{\underline{0} k}+b_{k} c_{d t}+\varepsilon_{d(j) t k}\right)$, where, $y_{d(j) t k}$ is the concentration of the compound $k$ in replicate $j$ of treatment $d$ at time $t, y_{\underline{0} t k}$ is the mean concentration of the compound $k$ in time $t$ in the control (untreated plant, $d=0$ ), $c_{d t}$ is a basic response pattern for every treatment $d$, and time $t, b_{k}$ is the weight of each compound with this basic response pattern, and $\varepsilon_{d(j) t k}$ is an error term with mean zero and variance $\sigma_{k}^{2}$. These parameters were generated through redundancy analysis (RDA) least-squares estimates from reduced-rank regression with concomitant variables (van den Brink and ter Braak, 1999), with $N=11$ replicates for each sampling time and treatment.

The values of $c_{\mathrm{dt}}$ for the treatment (treatment effect) were plotted as vertical axis (first principal component, PRC1) over sampling time generating a PRC diagram, with a curve for each treatment, that describes the dynamic changes in the blend of volatiles released by the plant. We compared the variation in volatile composition in damaged and undamaged soybean, the latter being our standard $\left(\mathrm{c}_{\mathrm{dt}}=\right.$ 0 ). The response variable weights (displayed on the right side of each diagram) allow evaluation of the contribution of each compound to the overall blend composition. The higher the values of the weight of the variable, the higher the contribution of the compound to the actual response pattern of the PRC.

PRC analysis was applied separately to each soybean cultivar, comparing the damaged and undamaged soybean. For each set of analyses, the significance of each PRC diagram was tested using an $F$-type test obtained by permutating (Monte Carlo permutation tests; 999 permutations) whole time series in the partial RDA from which the PRC was obtained. A second series of permutation tests (individual contrasts) was performed within each sampling date to determine if differences indicated by the PRC diagram between treatments were statistically significant. 
These analyses were carried out using the software CANOCO 4.5 for Windows (ter Braak and Šmilauer, 2002). The data from the main volatile compounds responsible for the treatment differences in PRC diagram were individually submitted to repeated measures MANOVA followed by contrasts formed within sampling time to compare induction treatments against the control, using the $t$ test (significance level 5\%).

\section{Results}

Olfactometer Bioassays with Egg Parasitoids When testing the resistant soybean cultivar Dowling, the egg parasitoid $T$. podisi responded preferentially to the odor of plants with herbivory (Herb; $\chi^{2}=7.67, P=0.005 ; \chi^{2}=8.06, P=0.005$ ) and herbivory plus egg deposition (HerbOvi; $\chi^{2}=9.60, P=$ $\left.0.002 ; \chi^{2}=8.06, P=0.005\right)$ when compared to undamaged plants (UD) after a 72 and $96 \mathrm{hr}$ treatment-period, respectively (Fig. 1). Telenomus podisi preferred volatiles from the resistant soybean cultivar IAC100 when these have been treated for $96 \mathrm{hr}$ by herbivory (Herb, $\chi^{2}=11.26, P=$ 0.001 ) and herbivory plus egg deposition (HerbOvi, $\chi^{2}=$ 8.06, $P=0.005$ ) to volatiles from undamaged (UD) plants. No preference was observed to the odors of cv IAC100 with other treatments at the different times evaluated (Fig. 2). For the susceptible cultivar Silvânia, T. podisi did not discriminate between odors emitted by undamaged plants and damaged plants regardless of the treatments and duration of treatment $(P>0.05)$ (Fig. 3).
Olfactometer Bioassays with Herbivore Females In the four-arm-olfactometer bioassays, E. heros females did not show a preference for the Herb-, HerbOvi-, Ovi-, or UDplants $\left(\chi^{2}, P>0.05\right)$ of any the three cultivars Silvânia, IAC100 and Dowling, or for undamaged plants of the three cultivars tested against air. This result was independent of the physiological state of the females (virgin starved, virgin fed, and mated fed).

Volatile Analysis The total amount of volatiles released by the soybean cultivar Dowling differed between treatments throughout the sampling times (treatment: $F=9.89 ; d . f .=3$, 56; $P=0.001$; interaction: Wilk's $\lambda=0.383 ;$ d.f. $=18,145 ; F=$ 3.25; $P=0.001$ ) (Fig. 4). The chemical profile of Dowling plants treated by herbivory (Herb), herbivory plus egg deposition (HerbOvi), egg deposition only (Ovi) differed when compared to undamaged plants (UD) at $48 \mathrm{hr}$ of treatment and at longer treatment periods (post-hoc pairwise comparisons by Tukey test, $P<0.05$ ). No difference was observed for treatment effects or its interaction with time for the cv IAC100 (treatment: $F=1.82 ;$ d.f. $=3,56 ; P=0.15$; interaction: Wilk's $\lambda=0.583$; d.f. $=18,145 ; F=1.61$; $P=0.06$ ) or cv Silvânia (treatment: $F=2.63 ; d . f .=3,56 ; P=$ 0.06 ; interaction: Wilk's $\lambda=0.607$; d.f. $=18,145 ; F=1.55$; $P=0.08$ ) (Fig. 4).

The chemical profile of the extracts obtained from the treatments Herb, HerbOvi, Ovi, and UD differed between the three cultivars Dowling, IAC100, and Silvânia. The compounds (Z)-2-octen-1-ol and (E)-2-octen-1-ol were identified only in cv Dowling; $(E)$-2-hexenyl acetate, and indole were identified in cv IAC100, while DMNT was

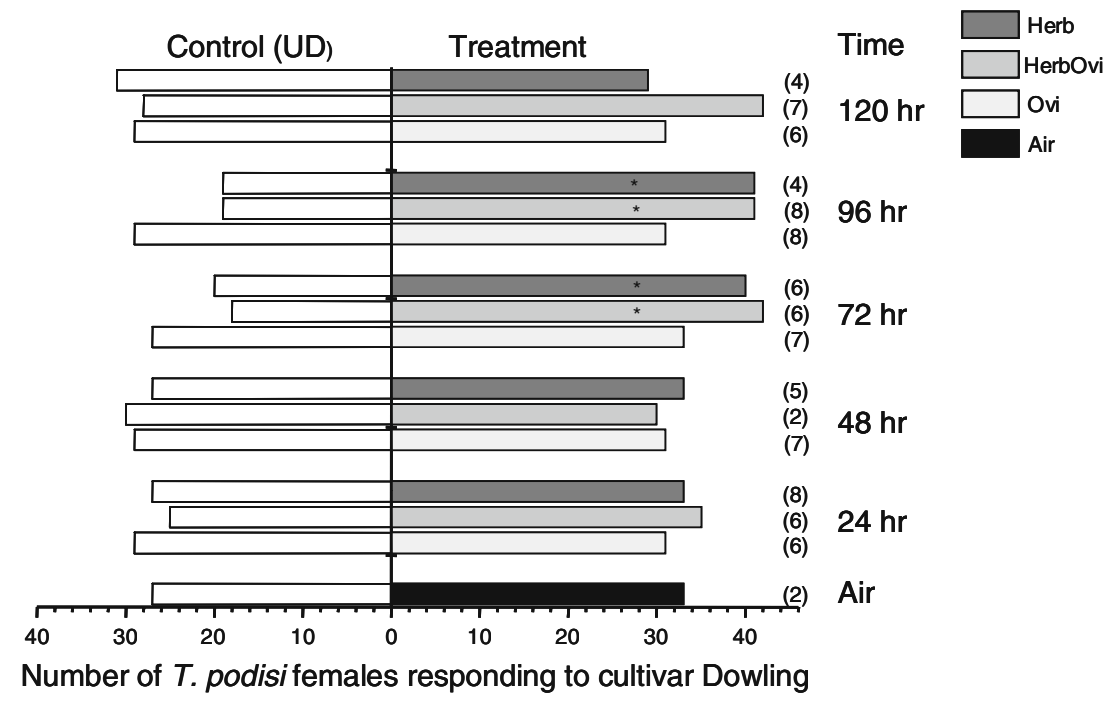

Fig. 1 Responses of the egg parasitoid Telenomus podisi in a Y-tube olfactometer to volatiles from soybean cultivar Dowling subjected to different treatments. $U D$ undamaged soybean, $O v i$ soybean plant with oviposition damage, HerbOvi soybean plant with herbivory +oviposition damage, Herb soybean plant with herbivory damage.
24, 48, 72, 96 and $120 \mathrm{hr}$ : time of plant treatment (induction time). Asterisks indicate significant differences $(P<0.05)$ between parasitoid responses to volatiles from different treatments: $\chi^{2}$ test on the proportion responding. Numbers in brackets represent the number of insects that did not respond to either of the treatments tested 
Fig. 2 Responses of the egg parasitoid Telenomus podisi in a Y-tube olfactometer to volatiles from soybean cultivar IAC100 subjected to different treatments. $U D$ undamaged soybean, $O v i$ soybean plant with oviposition damage, HerbOvi soybean plant with herbivory+oviposition damage, Herb soybean plant with herbivory damage. $24,48,72,96$ and $120 \mathrm{hr}$ : time of plant treatment (induction time). Asterisks indicate significant differences $(P<0.05)$ between parasitoid responses to volatiles from different treatments: $\chi^{2}$ test on the proportion responding. Numbers in brackets represent the number of insects that did not respond to either of the treatments tested

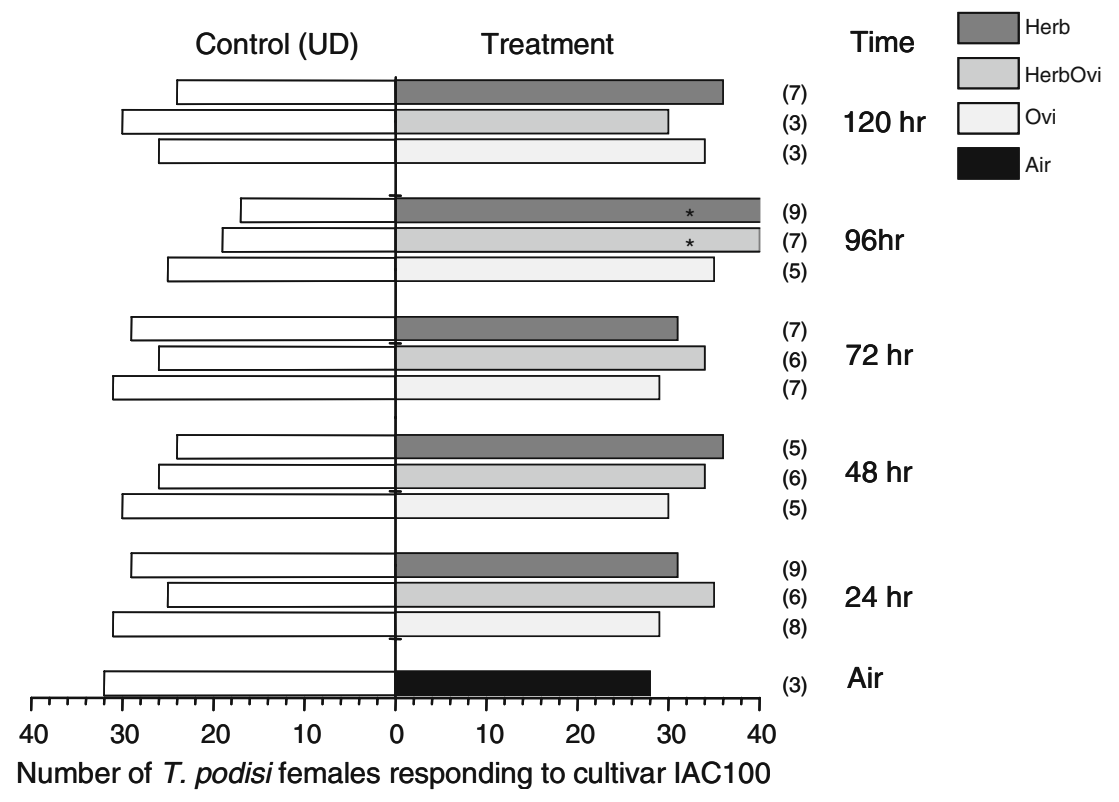

identified only in cv Silvânia (Table 1). The cultivars also emitted common compounds, such as the green leaf volatile (Z)-3-hexenyl acetate; the terpenoids camphene, limonene, $\alpha$-humulene, $\beta$-caryophyllene, $(E, E)$ - $\alpha$-farnesene, TMTT, and the shikimic acid derivatives benzothiazole, benzaldehyde, and methyl salicylate. In addition, some compounds were released in higher quantities by damaged soybean when compared to undamaged soybean (Table 1).

Soybean Cultivar Dowling The PRC analysis of the plant volatiles released showed that cv Dowling had a consistent variability over time between treatments. Of the total variance in the blend composition of volatiles released, $8.6 \%$ is explained by sampling times and $12 \%$ is explained by induction treatments. The variance exhibited in the first PRC axis was highly significant (Monte Carlo permutation test $F=35.0, P=0.001$ ), and explained $63.0 \%$ of the variation in the blend composition due to interactions between sampling times and induction treatments (Fig. 5). At $24 \mathrm{hr}$ after damage, the analysis did not show a significant difference, indicating that the blends of the four treatments were similar. From $48 \mathrm{hr}$ onward, PRC showed a

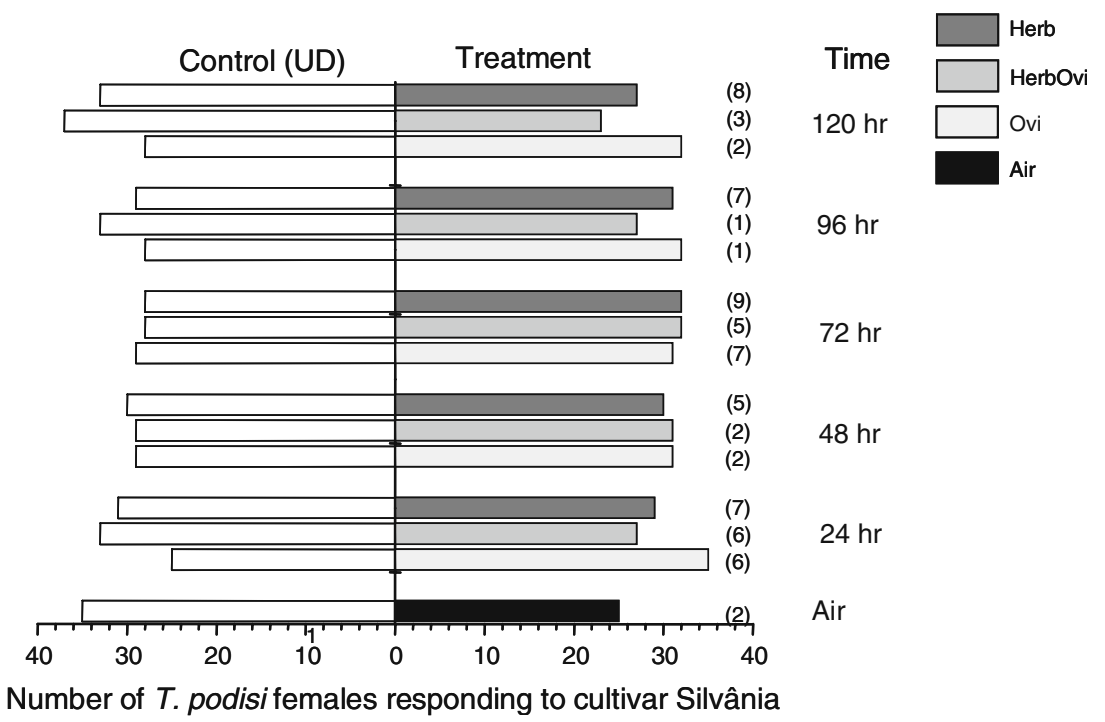

Fig. 3 Responses of the egg parasitoid Telenomus podisi in a Y-tube olfactometer to volatiles from soybean cultivar Silvânia subjected to different treatments. $U D$ undamaged soybean, $O v i$ soybean plant with oviposition damage, HerbOvi soybean plant with herbivory +oviposition damage, Herb soybean plant with herbivory damage.
24, 48, 72, 96 and $120 \mathrm{hr}$ : time of plant treatment (induction time). Asterisks indicate significant differences $(P<0.05)$ between parasitoid responses to volatiles from different treatments: $\chi^{2}$ test on the proportion responding. Numbers in brackets represent the number of insects that did not respond to either of the treatments tested 

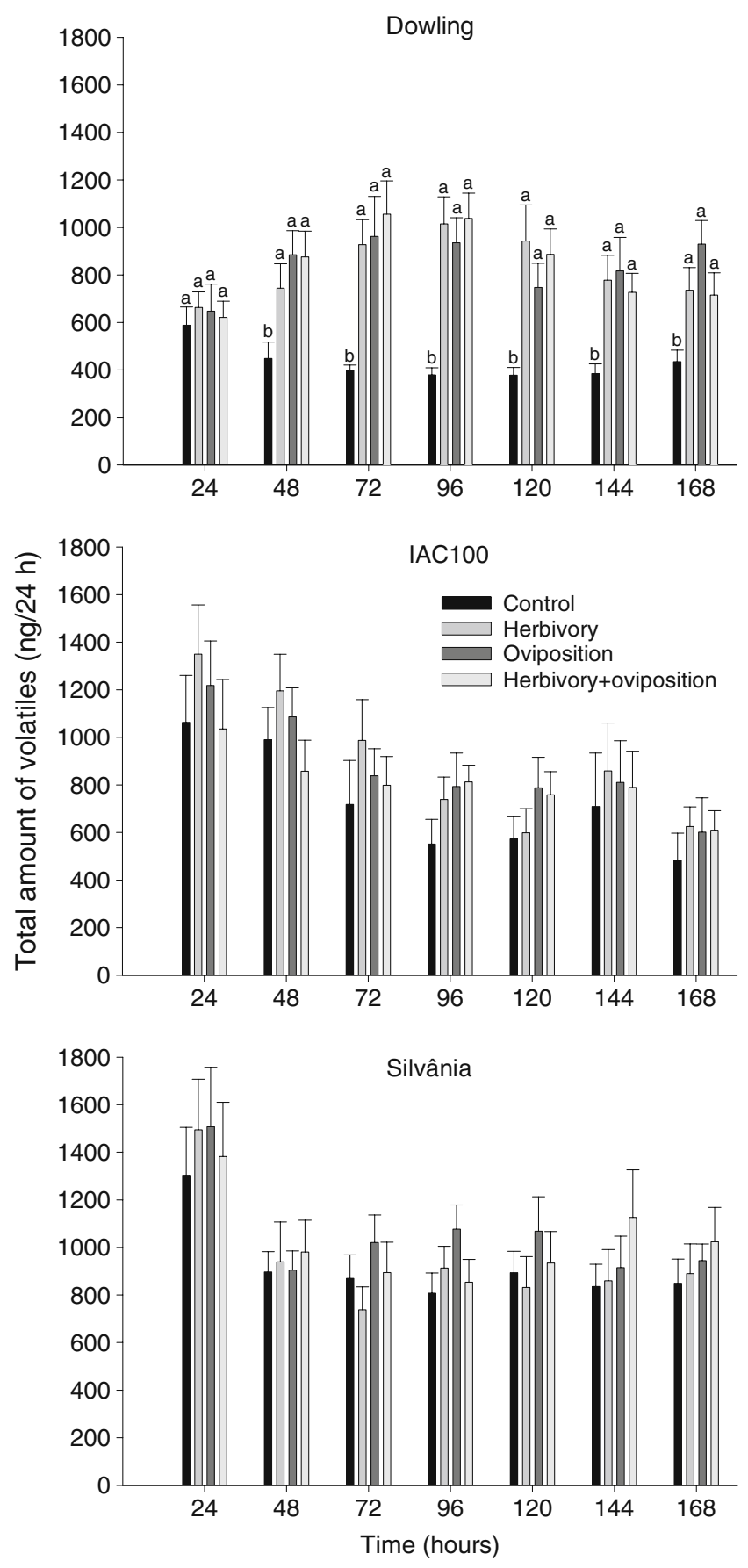

Fig. 4 Total amount of volatiles (mean + SEM) obtained from undamaged plants (control) and plants submitted to the treatments herbivory, oviposition, and herbivory+oviposition for soybean cultivars Dowling, IAC100, and Silvânia. The increase in the amount of volatiles released by damaged plants of cultivar Dowling was significant after $48 \mathrm{hr}$. For cultivars IAC100 and Silvânia there was no significant difference between treatments and its interactions with time (MANOVA for repeated measures, $P>0.05$ ). Means followed by the same letter within each sampling date are not significantly different by the Tukey's test at $P>0.05$ clear divergence in curves of the treatments when compared to the undamaged soybean (Fig. 5).

All variable weights $\left(b_{k}\right)$ showed on the right side of the PRC diagram were positive (Fig. 5), which means that all compounds were positively associated with the pattern of changes in the volatile blend. Compounds with weight values higher than 0.5 contribute to the overall volatile blend response (van den Brink and ter Braak, 1999) and the greater the $b_{k}$ value, the higher the influence on the blend response. Thus, $(E, E)-\alpha$-farnesene, methyl salicylate, $(Z)-3$ hexenyl acetate, and $(E)$-2-octen-1-ol were the main compounds that contributed $\left(b_{k}\right.$ absolute values $\left.>1.0\right)$ to the divergence between treatments and control for the $\mathrm{cv}$ Dowling (Fig. 5).

A significant interaction between treatment and time (MANOVA for repeated measures, $P<0.05$ ) was found when data for the main compounds of cultivar Dowling were analyzed individually (Fig. 6). Plants with the treatments Herb and HerbOvi differed from UD plants (contrasts within sampling date; $t$ test, $P<0.05$ ), releasing significantly higher quantities of the same compounds as indicated by PRC analysis (Fig. 6).

Soybean Cultivars IAC100 and Silvânia No significant treatment effect on the volatile blend composition was observed in PRC analysis for the cultivars IAC100 $(F=1.9$, $P=0.073$; Fig. 7, Table 1) and Silvânia $(F=10.4, P=0.104$; Fig. 8, Table 1). The variable weights $\left(b_{k}\right)$ displayed in the PRC diagrams showed low values, ranging between -0.5 and 0.5, for all compounds sampled (Figs. 7 and 8).

Although no differences were observed by PRC for IAC100, some compounds were released in higher quantities by plants with the treatments Herb and HerbOvi when compared to UD and Ovi (Table 1). When we analyzed the compounds individually (MANOVA for repeated measures, $P<0.05),(Z)$-3-hexenyl acetate $\left(t_{59,3}=\right.$ 2.031. $P=0.055)$, methyl salicylate $\left(t_{59,3}=2.159, P=0.035\right)$, and $(E, E)$ - $\alpha$-farnesene $\left(t_{48,3}=1.909, P=0.061\right)$ were released in significantly or marginally non-significantly higher amounts from plants subjected to 72-hr herbivory (Herb) when compared to undamaged plants (UD). (Z)-3Hexenyl acetate $\left(t_{59,3}=2.071, P=0.043\right)$, methyl salicylate $\left(t_{59,3}=1.834, P=0.072\right)$ and $(E, E) \alpha$-farnesene $\left(t_{55,3}=\right.$ $2.820, P=0.006)$ were released in significantly or marginally non significantly higher amounts from plants subjected to $96 \mathrm{hr}$ herbivory-plus-oviposition (HerbOvi) when compared to undamaged ones (UD). (E,E)- $\alpha$-farnesene $\left(t_{55,3}=2.322, P=0.023\right)$ was released in significantly higher amounts from plants after $96 \mathrm{hr}$ herbivory (Herb) when compared to undamaged plants (UD). The quantities of compounds released by Silvânia also were analyzed by MANOVA for repeated measures, but they did not differ among treatments. 
Table 1 Volatiles from differently treated soybean cultivars Dowling, IAC100, and Silvânia

\begin{tabular}{|c|c|c|c|c|}
\hline \multirow[t]{2}{*}{ Compounds } & \multicolumn{4}{|c|}{ Amounts of volatiles [ng $72-96 \mathrm{hr}]^{\mathrm{a}}$} \\
\hline & Treatment $^{\mathrm{b}}$ UD & Herb & Ovi & HerbOvip \\
\hline \multicolumn{5}{|l|}{ Dowling } \\
\hline Camphene & $14.8 \pm 2.4$ & $17.9 \pm 3.8$ & $37.1 \pm 9.6$ & $26.4 \pm 8.2$ \\
\hline Benzaldehyde & $13.6 \pm 2.9$ & $20.5 \pm 4.2$ & $18.4 \pm 5.1$ & $27.4 \pm 9.9$ \\
\hline (Z)-3-Hexenyl acetate & $92.5 \pm 19.0 \mathrm{a}$ & $226.4 \pm 64.9 \mathrm{~b}$ & $185.0 \pm 39.2 \mathrm{a}$ & $278.6 \pm 51.4 \mathrm{~b}$ \\
\hline Limonene & $31.2 \pm 6.8$ & $41.1 \pm 8.0$ & $62.9 \pm 11.9$ & $48.0 \pm 9.5$ \\
\hline$(Z)$-2-Octen-1-ol ${ }^{\mathrm{c}}$ & $20.2 \pm 2.0 \mathrm{a}$ & $39.4 \pm 10.9 \mathrm{a}$ & $85.4 \pm 16.9 b$ & $70.7 \pm 17.2 b$ \\
\hline$(E)-2-O c t e n-1-o l^{\mathrm{c}}$ & $50.6 \pm 8.5 \mathrm{a}$ & $117.3 \pm 21.4 \mathrm{~b}$ & $218.9 \pm 52.9 \mathrm{~b}$ & $204.8 \pm 60.6 \mathrm{~b}$ \\
\hline Methyl salicylate & $115.3 \pm 8.4 \mathrm{a}$ & $437.8 \pm 43.8 b$ & $240.8 \pm 39.5 b$ & $462.6 \pm 61.4 b$ \\
\hline Benzothiazole & $13.4 \pm 2.4$ & $24.6 \pm 3.6$ & $35.7 \pm 14.1$ & $15.0 \pm 2.6$ \\
\hline$(E)$-2-Decenal & $9.1 \pm 3.4$ & $5.5 \pm 1.3$ & $17.9 \pm 4.4$ & $16.7 \pm 4.8$ \\
\hline$\beta$-Caryophyllene & $30.2 \pm 8.5$ & $54.2 \pm 13.2$ & $57.8 \pm 12.9$ & $50.6 \pm 11.5$ \\
\hline$\alpha$-Humulene & $42.6 \pm 7.0$ & $52.0 \pm 10.6$ & $92.1 \pm 22.0$ & $85.6 \pm 16.9$ \\
\hline$(E, E)$ - $\alpha$-Farnesene & $213.8 \pm 24.0 \mathrm{a}$ & $623.4 \pm 75.1 \mathrm{~b}$ & $526.2 \pm 74.8 b$ & $562.2 \pm 66.9 \mathrm{~b}$ \\
\hline TMTT & $55.9 \pm 10.7$ & $114.0 \pm 36.8$ & $94.2 \pm 25.9$ & $90.9 \pm 22.9$ \\
\hline \multicolumn{5}{|l|}{ IAC100 } \\
\hline$(E)-2$-Hexenal & $16.6 \pm 7.9$ & $32.0 \pm 18.6$ & $12.2 \pm 6.3$ & $39.1 \pm 18.1$ \\
\hline (E)-2-Hexen-1-ol & $24.7 \pm 10.4$ & $12.2 \pm 4.4$ & $15.1 \pm 6.4$ & $13.5 \pm 4.4$ \\
\hline (Z)-3-Hexen-1-ol & $29.8 \pm 18.8$ & $10.6 \pm 2.6$ & $20.3 \pm 12.5$ & $10.7 \pm 2.4$ \\
\hline Camphene & $36.7 \pm 13.4$ & $48.4 \pm 22.2$ & $47.6 \pm 16.9$ & $29.1 \pm 11.5$ \\
\hline Benzaldehyde & $37.2 \pm 18.1$ & $19.1 \pm 4.7$ & $32.1 \pm 12.8$ & $19.9 \pm 4.2$ \\
\hline (Z)-3-Hexenyl acetate & $40.8 \pm 16.3 \mathrm{a}$ & $123.3 \pm 52.6 \mathrm{~b}$ & $73.3 \pm 19.0 \mathrm{a}$ & $97.2 \pm 30.9 b$ \\
\hline$(E)$-2-Hexenyl acetate & $22.7 \pm 16.8$ & $52.8 \pm 34.9$ & $26.4 \pm 11.9$ & $17.2 \pm 1.7$ \\
\hline Limonene & $87.7 \pm 37.9$ & $54.5 \pm 13.3$ & $110.6 \pm 31.8$ & $64.4 \pm 22.5$ \\
\hline (E)-Ocimene & $51.1 \pm 13.3$ & $65.8 \pm 15.6$ & $102.3 \pm 60.4$ & $112.5 \pm 18.3$ \\
\hline Linalool & $64.5 \pm 18.4$ & $94.0 \pm 22.9$ & $166.3 \pm 58.8$ & $118.9 \pm 22.7$ \\
\hline Methyl salicylate & $36.6 \pm 15.2 \mathrm{a}$ & $123.9 \pm 9.8 b$ & $78.9 \pm 30.8 \mathrm{a}$ & $135.1 \pm 50.1 \mathrm{~b}$ \\
\hline Benzothiazole & $15.7 \pm 4.7$ & $21.3 \pm 42.6$ & $14.5 \pm 4.3$ & $16.7 \pm 4.2$ \\
\hline Indole & $20.0 \pm 8.2$ & $12.6 \pm 3.7$ & $21.0 \pm 8.2$ & $19.7 \pm 4.2$ \\
\hline$\beta$-Caryophyllene & $101.9 \pm 43.5$ & $89.2 \pm 5.0$ & $83.6 \pm 21.3$ & $90.3 \pm 22.3$ \\
\hline Geranyl acetone & $107.7 \pm 36.5$ & $91.3 \pm 28.3$ & $122.5 \pm 27.2$ & $105.8 \pm 26.8$ \\
\hline$\alpha$-Humulene & $271.9 \pm 68.7$ & $126.9 \pm 45.3$ & $198.4 \pm 65.4$ & $279.2 \pm 77.2$ \\
\hline$(E, E)$ - $\alpha$-Farnesene & $149.5 \pm 42.7 \mathrm{a}$ & $362.9 \pm 86.8 b$ & $247.9 \pm 64.3 \mathrm{a}$ & $354.2 \pm 62.4 \mathrm{~b}$ \\
\hline TMTT & $67.3 \pm 24.1$ & $82.9 \pm 18.9$ & $84.1 \pm 20.3$ & $70.3 \pm 17.9$ \\
\hline \multicolumn{5}{|l|}{ Silvânia } \\
\hline$(E)$-2-Hexenal & $26.1 \pm 12.1$ & $52.7 \pm 19.8$ & $64.7 \pm 23.6$ & $47.6 \pm 18.7$ \\
\hline (E)-2-Hexen-1-ol & $35.7 \pm 7.6$ & $20.9 \pm 6.0$ & $41.2 \pm 11.4$ & $45.5 \pm 13.1$ \\
\hline (Z)-3-Hexen-1-ol & $26.2 \pm 7.1$ & $20.8 \pm 9.8$ & $42.4 \pm 12.8$ & $32.8 \pm 10.2$ \\
\hline Camphene & $42.9 \pm 6.1$ & $83.2 \pm 36.2$ & $79.6 \pm 24.9$ & $46.5 \pm 7.7$ \\
\hline Benzaldehyde & $21.0 \pm 4.3$ & $19.0 \pm 2.7$ & $50.2 \pm 11.3$ & $48.0 \pm 14.2$ \\
\hline (Z)-3-Hexenyl acetate & $86.2 \pm 19.4$ & $52.1 \pm 22.9$ & $75.6 \pm 24.5$ & $76.4 \pm 30.9$ \\
\hline Limonene & $74.4 \pm 16.9$ & $96.9 \pm 18.6$ & $175.3 \pm 38.8$ & $137.2 \pm 28.6$ \\
\hline (E)-Ocimene & $105.5 \pm 22.2$ & $119.7 \pm 26.1$ & $179.9 \pm 18.9$ & $152.9 \pm 32.9$ \\
\hline Linalool & $134.7 \pm 20.6$ & $144.9 \pm 24.0$ & $169.3 \pm 27.9$ & $141.5 \pm 21.3$ \\
\hline DMNT & $41.5 \pm 11.7$ & $46.2 \pm 11.1$ & $61.0 \pm 9.9$ & $44.0 \pm 9.2$ \\
\hline Methyl salicylate & $30.1 \pm 8.8$ & $46.3 \pm 11.8$ & $45.9 \pm 11.3$ & $46.5 \pm 11.6$ \\
\hline Benzothiazole & $13.9 \pm 2.9$ & $19.4 \pm 6.3$ & $13.4 \pm 3.5$ & $23.7 \pm 8.9$ \\
\hline$\beta$-Caryophyllene & $31.3 \pm 9.2$ & $92.1 \pm 37.2$ & $41.5 \pm 13.1$ & $42.7 \pm 18.2$ \\
\hline
\end{tabular}


Table 1 (continued)

\begin{tabular}{lcccr}
\hline \multirow{2}{*}{ Compounds } & \multicolumn{2}{c}{ Amounts of volatiles $[\mathrm{ng} 72-96 \mathrm{hr}]^{\mathrm{a}}$} & & \\
\cline { 2 - 5 } & Treatment $^{\mathrm{b}} \mathrm{UD}$ & Herb & Ovi & \\
\hline Geranyl acetone & $138.8 \pm 30.8$ & $164.5 \pm 29.2$ & $167.1 \pm 38.5$ & \\
$\alpha$-Humulene & $140.0 \pm 27.3$ & $192.6 \pm 39.8$ & $226.0 \pm 62.9$ & $219.7 \pm 53.0$ \\
$(E, E)$ - $\alpha$-Farnesene & $153.8 \pm 25.1$ & $123.3 \pm 19.2$ & $222.8 \pm 46.5$ & $201.8 \pm 44.4$ \\
TMTT & $66.7 \pm 15.8$ & $44.6 \pm 15.1$ & $72.4 \pm 19.4$ & $49.8 \pm 17.4$ \\
\hline
\end{tabular}

${ }^{\text {a }}$ Mean values ( \pm SEM) calculated from 22 samples obtained by aerations during the period spanning $72-96 \mathrm{hr}$ after the start of damage

${ }^{\mathrm{b}}$ (UD) undamaged plants; or plants submitted to treatments Herbivory (Herb), Oviposition (Ovi) and Herbivory+Oviposition (HerbOvi) damage. Means followed by the same letter within a line are not significantly different by the MANOVA at $P>0.05$. TMTT $((E, E)-4,8,12$-trimethyltrideca- $1,3,7,11-$ tetraene), DMNT ((E)-4,8-dimethylnona-1,3,7-triene)

${ }^{\mathrm{c}}$ Tentatively identified compounds

\section{Discussion}

In this study, by comparing the susceptible cultivar Silvânia and the resistant cultivars Dowling and IAC100, it is apparent that each cultivar has a different response to herbivore damage, eliciting different responses by the egg parasitoid. The results support our hypothesis that the level of indirect defense in response to damage by herbivores in resistant soybean cultivars is different from that of susceptible cultivars. We could show that the resistant cultivars (here Dowling and IAC100) showed stronger induction of indirect defense; they show a higher production of volatile compounds in response to herbivore attack and a stronger response by the egg parasitoid, $T$. podisi, to volatiles released from plants with herbivory and herbivory+oviposition when compared to undamaged plants. In addition, the results obtained in this study agree with those presented by previous work on induced plant responses to oviposition by Pentatomidae (Colazza et al., 2004a, b; Moraes et al., 2008), where oviposition itself (without herbivory) did not induce changes of plant odors that are attractive to the egg parasitoids.

However, egg-laying by the pentatomid E. heros on the cultivars Dowling and IAC100 changes the plant volatile profile; we have detected differences in the

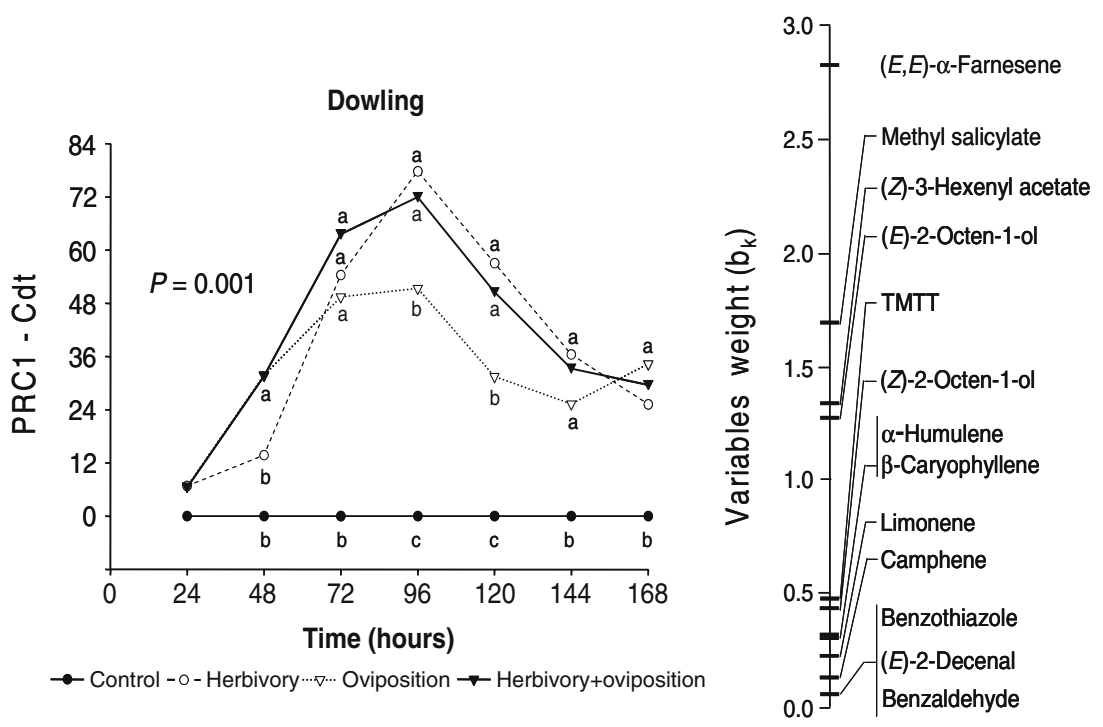

Fig. 5 PRC diagram and variables weights $\left(b_{k}\right)$ based on volatile blends released by soybean plants of the cultivar Dowling, on seven sampling days. The lines represent the response pattern of soybean plants to different treatments in time. The $P$-value indicates significance of the PRC diagram over all sampling times based on $F$-type permutation test. On each date, values of $C_{d t}$ differ significantly between treatments that do not share the same letter code $(a-c)$; shared or omitted letter codes denote contrasts that do not differ significantly by the Monte Carlo permutation tests at $P<0.05$. The higher (absolute values) the variable weight, the more closely the compound response pattern follows the deviation pattern (from the control, $C_{d t}=0$ line) indicated on the PRC 

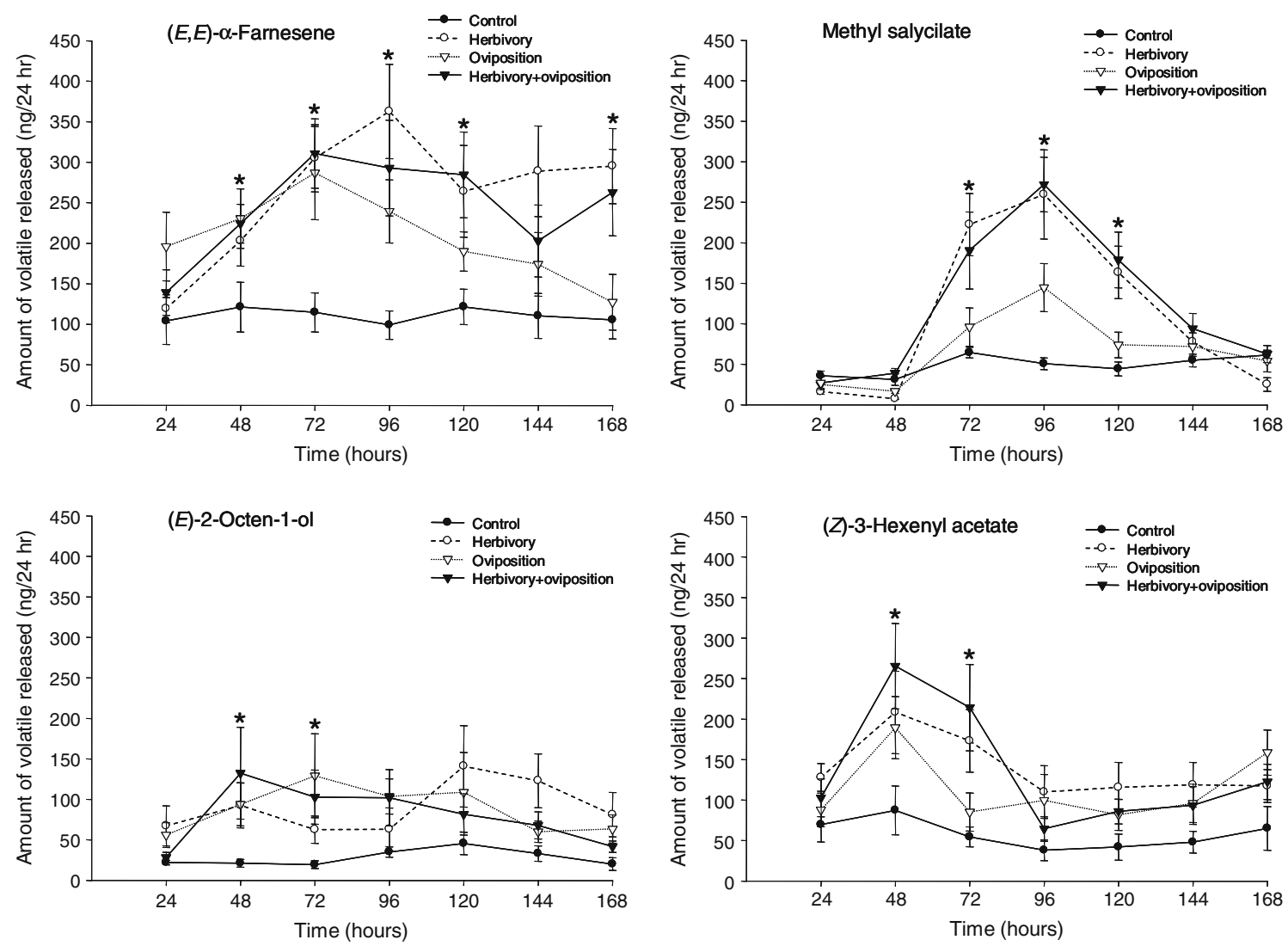

Fig. 6 Amounts (mean \pm SEM) of principal volatile compounds released by undamaged soybean (control) and soybean plants submitted to herbivory, oviposition and herbivory+oviposition damage, for cultivar Dowling. Bars represent the standard error of the

mean. Means marked with an asterisk indicate significant differences $(P<0.05)$ between induction treatments and control (within a sampling date), $t$ test
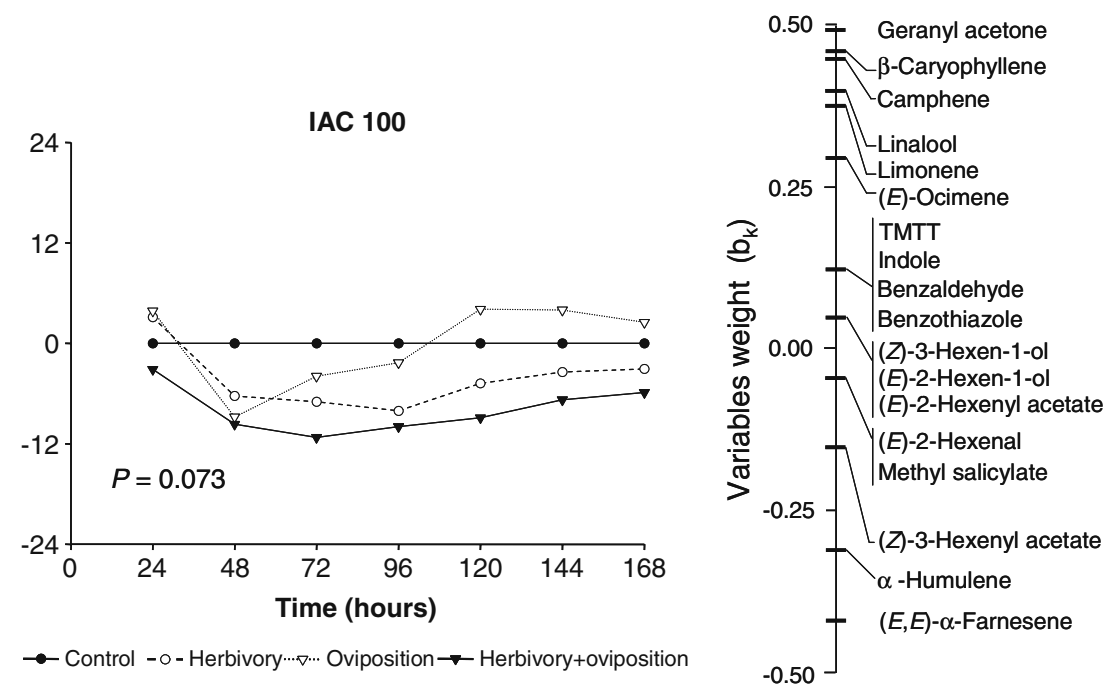

Fig. 7 PRC diagram and variables weights $\left(b_{k}\right)$ based on volatile blends released by soybean plants of the cultivar IAC 100, on seven sampling occasions. The lines represent the response pattern of soybean plants to different treatments in time. The $P$-value indicates significance of the PRC diagram over all sampling times based on $F$ - type permutation test. The first PRC did not display a significant part of the treatment variance (Monte Carlo permutation test, $P>0.05$ ), indicating that no significant induction treatment effect on the volatile blend composition was detected. All compounds showed low values for the variables weights $\left(b_{k}<0.5\right)$ 

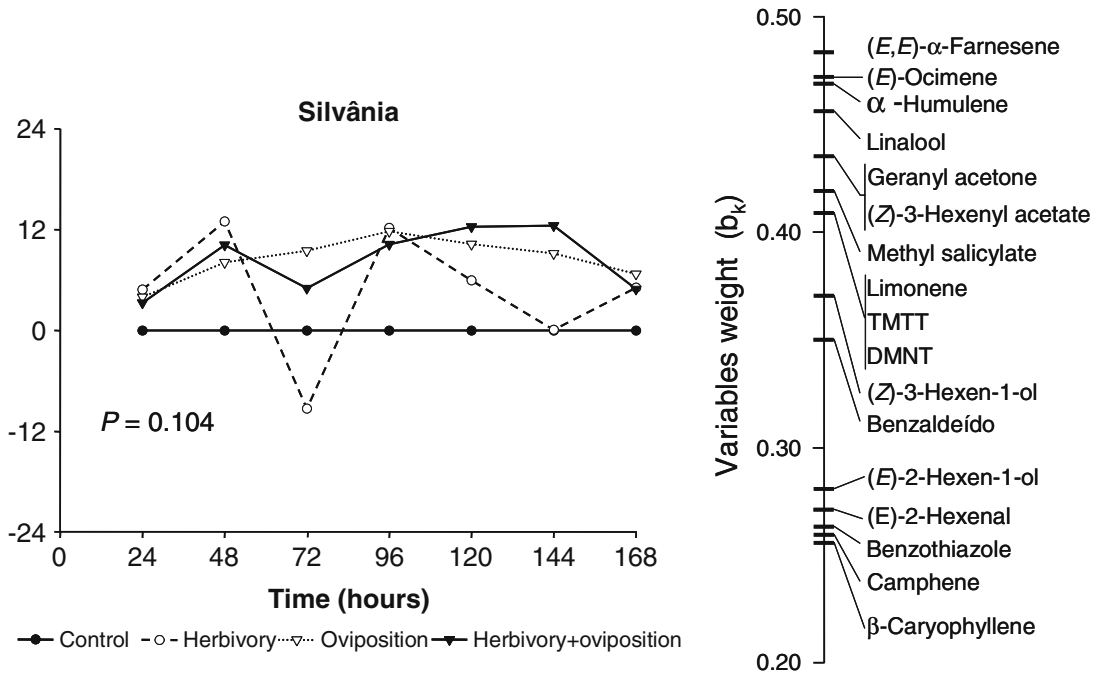

Fig. 8 PRC diagram and variables weights $\left(b_{k}\right)$ based on volatile blends released by soybean plants of the cultivar Silvânia, on seven sampling occasions. The lines represent the response pattern of soybean plants to different treatments in time. The $P$-value indicates significance of the PRC diagram over all sampling times based on $F$ - type permutation test. The first PRC did not display a significant part of the treatment variance (Monte Carlo permutation test, $P>0.05$ ), indicating that no significant induction treatment effect on the volatile blend composition was detected. All compounds showed low values for the variables weights $\left(b_{k}<0.5\right)$ volatile blends of these cultivars between undamaged, herbivory- and herbivory+oviposition-damaged soybean plants. Moraes et al. (2008) suggested that the egg parasitoid T. podisi was not attracted to the blend of volatiles produced by herbivory+oviposition and oviposition damaged soybean (cv BR-16), probably due the switching-off of jasmonate signaling caused by oviposition damage. In contrast, the results presented here suggest that oviposition did not switch off jasmonic acid-dependent plant defense because herbivory+oviposition-damaged soybean plants also attracted the natural enemy.

The lack of attraction of the egg parasitoid to oviposition-damaged plants could be explained if the response of the plant is not systemic. When the stink bug lays eggs on the leaves, there is a localized necrosis below and around the eggs (personal observation), which suggests a hypersensitive response (HR) by the plant, isolating the damaged area in a way similar to plant-pathogen responses (Walling, 2000; Kaloshian and Walling, 2005). What induces soybean plants to respond with necrosis to oviposition needs further study, but could be due to microorganisms or chemicals from the oviposition secretion that induce the HR. We are trying to elucidate this phenomenon by studying the chemistry of the saliva and the oviposition secretions.

The PRC analysis used in this work showed the main compounds induced by herbivore damage and the interaction between the damage time and the volatiles released by the soybean plant. The PRC analysis is a multivariate method that is commonly used to aid in impact assessments of pollutant stress on aquatic and terrestrial biological communities in ecotoxicological studies (van den Brink and ter Braak, 1999; van den Brink et al., 2003), and application to other ecological aspects (Torres and Ruberson, 2005; Poelman et al., 2010) has proceeded rapidly. The great advantage of the PRC compared to other multivariate analysis is that it is possible to evaluate the variation of the compounds over time and the importance of each compound in a blend. Furthermore, there is no limitation on the number of variables and normality of the data is unnecessary.

The PRC results suggest that the increase of $(E, E)-\alpha-$ farnesene, methyl salicylate, (Z)-3-hexenyl acetate, and $(E)$-2-octen-1-ol in the total blend have an effect on parasitoid behavior, but the role of these compounds, individually, on the attraction of the egg parasitoid $T$. podisi needs to be evaluated. The attraction of parasitoids and predators to herbivore induced volatiles is often attributed to the relative contribution of each compound in the blend (D'Alessandro et al., 2006, 2009; Pareja et al., 2009), and not all herbivore-induced compounds are important for changing insect behavior. For example, two important compounds in the herbivore-induced volatile blend, indole in maize, Zea mays, and methyl salicylate in Arabidopsis sp, were not the key compounds responsible for the attraction of the parasitoids tested (D'Alessandro et al., 2006, 2009; Snoeren et al., 2010).

Telenomus podisi did not distinguish among the odors of damaged and undamaged plants for any treatment in $\mathrm{cv}$ Silvânia, probably because the volatile compounds released by undamaged and damaged Silvânia soybean are too similar for a discrimination. Vet et al. (1998) suggested that 
an insect does not discriminate between odor sources because it is not able to do so, or because the odor is not in the right conditions for the discrimination, i.e., the compounds released by the plant are not in the correct concentration or proportion to be perceived by the natural enemies as a cue indicating the presence of the host. The egg parasitoid $T$. podisi discriminated between volatiles released from differently treated cv Dowling and IAC100, respectively. However, no preference for odor of any treatment of the susceptible Silvânia cultivar was detected; thus, we suggest that the susceptible cultivar was not induced by herbivore damage.

Herbivory-induced plant volatiles are important cues for host foraging behavior of parasitoids. Therefore, maintaining and even enhancing the attractiveness of crop plants to natural enemies should be considered an important trait when breeding new crop varieties. However, these possibilities may sometimes be constrained by the effect of these changes on the attractiveness of the plant to herbivorous pests, as volatiles that attract more natural enemies could also attract more herbivores (Cortesero et al., 2000). Thaler (1999) mentioned that it is advantageous for herbivores to avoid laying eggs on induced plants because such plants are likely to host other herbivores, which are potential competitors for second offspring herbivores, and can also attract a population of natural enemies. The results obtained in this work showed that $E$. heros does not use herbivoreinduced volatiles as cues to distinguish between damaged and undamaged plants, or to distinguish between cultivars, but $E$. heros females responded preferentially to undamaged soybean $\left(\chi^{2}, P=0.002\right)$ compared to air, suggesting that $E$. heros uses the volatiles from soybean plants to locate its host-plant (results not shown).

The cv Dowling and IAC100 are known to have in their reproductive stage an antixenotic and antibiotic effect against aphids and stink bugs, respectively (Carrão-Panizzi and Kitamura, 1995; Li et al., 2004, 2008). Recently, field experiments showed that population levels of stink bugs colonizing cv Dowling and cv IAC100 were lower than on cv Silvânia suggesting a differential resistance/susceptibility (Laumann et al., 2008). Different studies suggested that the resistance during the reproductive stage of soybean could be related to the amount of isoflavonoids (Rao et al., 1990; Hoffmann-Campo et al., 2001; Piubelli et al., 2003, 2005). Experiments are needed to determine the amount of isoflavonoids during the different physiological stages of soybean plants to evaluate if there is a relation between direct and indirect defense and the quantities of volatile organic compounds.

In summary, the results suggest that the herbivorous stink bug $E$. heros induces the indirect defense of the resistant soybean cultivars Dowling and IAC100, and that the egg parasitoid T. podisi is attracted to the volatiles released by herbivory- and herbivory+oviposition-damaged plants of these cultivars. In olfactometer bioassays, E. heros did not distinguish between damaged and undamaged soybean nor between resistant and susceptible cultivars. In addition, the resistant cultivar Dowling and IAC100 showed consistency in the main volatile compounds induced: $(E, E)$ - $\alpha$-farnesene, methyl salicylate, $(Z)-3$-hexenyl acetate. Further laboratory studies are necessary to investigate the importance of these compounds for attraction of the egg parasitoid T. podisi. Once understood, these volatile compounds could help to develop new strategies for control of E. heros using natural enemies in soybean crops.

Acknowledgements We thank H. Santos and D. Tiburcio for helping with laboratory rearing of the insects, and Jeffrey Aldrich and Michael Birkett for providing synthetic standards. We are grateful to Dr. Mark Horn International Consultant at Embrapa Genetic Resources and Biotechnology, to Monika Hilker and Martin Pareja for comments that improved the manuscript and for revising the English. We also thank the Post-Graduate Animal Biology program of University of Brasília (UnB) for use of their facility. This work received financial support from the Brazilian Council for Scientific and Technological Development (CNPq) through a grant to Mirian F.F. Michereff, International Foundation for Science IFS, Distrito Federal Research Foundation (FAP-DF) and Brazilian Corporation of Agricultural Research (EMBRAPA).

\section{References}

BARTLETT, R. 2008. Negative interactions between chemical resistance and predators affect fitness in soybeans. Ecol. Entomol. 33:673-678.

Borges, M., Schmidt, F. G. V., SuJi, E. R., Medeiros, M. A., Mori, K., Zarbin, P. H. G., and Ferreira, J. T. B. 1998. Field responses of stink bugs to the natural and synthetic pheromone of the Neotropical brown stink bug, Euschistus heros (Heteroptera: Pentatomidae). Physiol. Entomol. 23:202-207.

CARrÃo-PANizZI, M. C. and KitAmURA, K. 1995. Isoflavone content in Brazilian soybean cultivars. Breed. Sci. 45:295-300.

Chen, M. S. 2008. Inducible direct plant defense against insect herbivores: A review. Insect Science 15:101-114.

Colazza, S., Fucarino, A., Peri, E., Salerno, G., Conti, E., and Bin, F. 2004a. Insect oviposition induces volatile emission in herbaceous plants that attracts egg parasitoids. J. Exp. Biol. 207:47-53.

Colazza, S., McElfresh, J. S., and Millar, J. G. $2004 \mathrm{~b}$. Identification of volatile synomones, induced by Nezara viridula feeding and oviposition on bean spp., that attract the egg parasitoid Trissolcus basalis. J. Chem. Ecol. 30:945-964.

Cortesero, A. M., Stapel, J. O., and Lewis, W. J. 2000. Understanding and manipulating plant attributes to enhance biological control. Biol. Control 17:35-49.

D'alessandro, M., Held, M., Triponez, Y., and Turlings, T. C. J. 2006. The role of indole and other shikimic acid derived maize volatiles in the attraction of two parasitic wasps. J. Chem. Ecol. 32:2733-2748.

D’Alessandro, M., Brunner, V., Von Mérey, G., and Turlings, T. C. J. 2009. Strong attraction of the parasitoid Cotesia marginiventris towards minor volatile compounds of maize. $J$. Chem. Ecol. 35:999-1008.

De Moraes, C. M., Mescher, M. C., and Tumlinson, J. H. 2001. Caterpillar-induced nocturnal plant volatiles repel conspecific females. Nature 410:577-580. 
DiCKE, M. 1999. Are herbivore-induced plant volatiles reliable indicators of herbivore identity to foraging carnivorous arthropods? Entomol. Exp. Appl. 91:131-142.

Fehr, W. R., Caviness, C. E., Burmood, D. T., and Pennington, J. S. 1971. Stage of development descriptions for soybeans, Glycine max (L.) Merrill. Crop Science 11:929-931.

Fritzsche Hoballah, M. E., and Turlings, T. C. J. 2001. Experimental evidence that plants under caterpillar attack may benefit from attracting parasitoids. Evol. Ecol. Res. 3:553-565.

GATEHouse, J. A. 2002. Plant resistance towards insect herbivores: A dynamic interaction. New Phytol. 156: 145-169.

GREEN, R. H. 1993. Application of repeated measures designs in environmental impact and monitoring studies. Aust. J. Ecol. 18:81-98.

HeIL, M. 2008. Indirect defence via tritrophic interactions. New. Phytol. 178:41-61.

HiLKer, M. and MeINERS, T. 2006. Early herbivore alert: Insect eggs induce plant defense. J. Chem. Ecol. 32: 1379-1397.

HofFmann-CAMPo, C. B., HARBorne, J. B., and MCCAFFERY, A. R. 2001. Pre-ingestive and post-ingestive effects of soya bean extracts and rutin on Trichoplusia ni growth. Entomol. Exp. Appl. 98:181-194.

HURLBERT, S. H. 1984. Pseudoreplication and the design of ecological field experiments. Ecol. Monogr. 54:187-211.

Jorge, L. A. C., Laumann, R. A., Borges, M., Moraes, M. C. B., Cruz, R. A., Milare, B. N., and Palhares, L. 2005. Software para avaliação do comportamento de insetos. São Carlos, SP. Embrapa Instrumentação Agropecuária. Circular Técnica, Vol. $30,7 \mathrm{p}$.

Kaloshian, I. and Walling, L. L. 2005. Hemipterans as plant pathogens. Annu. Rev. Phytopathol. 43:491-521.

Laumann R. A., Farias Neto, A. L., Blassioli-Moraes, M. C., Silva, A. P., Vieira, C. R., Moraes, S. V. P., Hoffman-CAmpo, C. B., and Borges, M. 2008. Dinâmica populacional de percevejos (Hemiptera:Pentatomidae) em diferentes genótipos de soja. In: IX Simpósio Nacional Cerrado; II Simpósio Internacional Savanas Tropicais, Brasília, DF. Desafios e estratégias para o equilíbrio entre sociedade, agronegócio e recursos naturais: anais. Planaltina, DF: Embrapa Cerrados, http://www. cpac.embrapa.br/download/747/t

LI, Y., HiLL, C. B., and HARTMAN, G. L. 2004. Effect of three resistant soybean genotypes on the fecundity, mortality and maturation of soybean aphid (Homoptera: Aphididae). J Econ. Entomol. 97:1106-1111.

Li, Y., Zou, J., Li, M., Bilgin, D. D., Vodkin, L.O., Hartman, G. L., and ClOUGH, S. J. 2008. Soybean defense responses to the soybean aphid. New. Phytol. 179:185-195.

Lin, C., Shen, B., Xu, Z., Köllner, T. G., Degenhardt, J., and DOONER, H. 2008. Characterization of monoterpene synthase gene tps 26, the ortholog of a gene induced by insect herbivory in maize. Plant Physiol. 146:940-951.

MCPHERSON, R. M. and Buss, G. R. 2007. Evaluation lepidopteran defoliation resistance in soybean breeding lines containing the stink bug (Hemipetra: Pentatomidae) resistance IAC100 cultivar in their pedigrees. J. Econ. Entomol. 100:962-968.

Moraes, M. C. B., LaumanN, R. A., Pires, C. S. S., SuJit, E. R., and BORGES, M. 2005. Induced volatiles in soybean and pigeon pea plants artificially infested with the Neotropical brown stink bug, Euschistus heros, and their effect on the egg parasitoid, Telenomus podisi. Entomol. Exp. Appl. 115:227-237.

Moraes, M. C. B., Pareja, M., Laumann, R. A., Hoffmann-CAmpo, C. B., and Borges, M. 2008. Response of the parasitoid Telenomus podisi to induced volatiles from soybean damaged by stink bug herbivory and oviposition. J. Plant. Int. 3:1742-1756.
Pareja, M., MohiB, A., Birkett, A. M., Dufour, S., and Glinwood, R. T. 2009. Multivariate statistics coupled to generalized linear models reveal complex use of chemicals cues by a parasitoid. Anim. Behav. 77:901-909.

Piubelli, G. C., Hoffmann-Campo, C. B., Arruda, I. C., FRANCHINI, J. C., and LARA, F. M. 2003. Flavonoid increase in soybean as a response to Nezara viridula injury and its effects on insect-feeding preference. J. Chem. Ecol. 29:1232-1232.

Piubelli, G. C., Hoffmann-Campo, C. B., Moscardi, F., Miyakubo, S. H., and Oliveira, M. C. N. 2005. Are chemical compounds important for soybean resistance to Anticarsia gemmatalis? J. Chem. Ecol. 31: 1509-1525.

Poelman, E. H., Van Loon, J. J. A., Van Dam, N. M., Vet, L. E. M., and DickE, M. 2010. Herbivore-induced plant responses in Brassica oleracea prevail over effects of constitutive resistance and result in enhanced herbivore attack. Ecol. Entomol. 35:240 247.

PricE, P. 1997. Insect Ecology. 3rd edn. P. 874. John Wiley \& Sons, New York.

RaO, K. V., Chattopabhyay, S. K., and Chandrasekhara RedDy, G. 1990. Flavonoids with mosquito larval toxicity. J. Agric. Food. Chem. 38:1427-1430.

Rasmann, S. and Turlings, T. C. J. 2008. First insights into specificity of belowground tritrophic interactions. Oikos 117:362-369.

SAS INSTITUTE. 2001. SAS User's Guide: Statistics, version 8.2, 6th edn. SAS Institute, Cary, NC.

Snoeren, T. A. L., Mumm, R., Poelman, E. H., YAng, Y., PICHERSKY, E., and DiCKE, M. 2010. The herbivore-induced plant volatile methyl salicylate negatively affects attraction of the parasitoid Diadegma semiclausum. J. Chem. Ecol. 36:479-489.

tER BRAAK, C. J. F. and ŠMILAUER, P. 2002. CANOCO Reference Manual and User's Guide to Canoco for Windows: Software for Canonical Community Ordination (version 4.5). Microcomputer Power, Ithaca, New York.

THALER, J. S. 1999. Jasmonate-inducible plant defences cause increased parasitism of herbivores. Nature 399:686-688.

Torres, J. B., and Ruberson, J. R. 2005. Canopy and grounddwelling predatory arthropods in commercial $\mathrm{Bt}$ and non-Bt cotton fields: patterns and mechanisms. Environ. Entomol. 34:1242-1256.

vAN dEN BRINK, P. J., and ter BraAK, C. J. F. 1999. Principal response curves: analysis of time dependent multivariate responses of biological community to stress. Environ. Toxicol. Chem. 18:138-148.

vAN dEN BRINK, P. J., vAN dEN BRINK, N. W., and tER BRAAK, C. J. F. 2003. Multivariate analysis of ecotoxicological data using ordination: demonstrations of utility on the basis of various examples. Aust. J. Ecotoxicol. 9:141-156.

Vet, L. E. M., Van Lenteren, J. C., Heymans, M., and Meelis, E. 1983. An airflow olfactometer for measuring olfactory responses of hymenopterous parasitoids and other small insects. Physiol. Entomol. 8:97-106.

Vet, L. E. M., De Jong, A. G., Franchi, E., and PapaJ, D. R. 1998. The effect of complete versus incomplete information on odour discrimination in a parasitic wasp. Anim. Behav. 55:1271-1279.

vON ENDE, C. N. 1993. Repeated-measures analysis: growth and other time-dependent measures. pp. 113-137 in: S. Scheiner and J. Gurevitch (eds). Design and Analysis of Ecological Experiments. Chapman \& Halland, New York.

WALLING, L. L. 2000. The myriad plant responses to herbivores. $J$. Plant Growth Regul. 19:195-216.

ZAR, J. H. 1998. Biostatistical Analysis. 1st edn. P. 929. Prentice Hall, London, UK. 